\title{
Low-Cycle Fatigue Properties of a Nickel-Based Superalloy Haynes 282 for Heavy Components
}

\author{
Junjing He (D, Rolf Sandström, and Sandro Notargiacomo
}

\author{
(Submitted August 23, 2016; in revised form December 13, 2016; published online April 4, 2017)
}

\begin{abstract}
Low-cycle fatigue (LCF) tests of the nickel-based superalloy Haynes 282 from a large forged ingot were conducted at 25 and $750{ }^{\circ} \mathrm{C}$ with total strain ranges from 0.7 to $1.7 \%$. Compared with other tests on this alloy, it was found that the LCF properties showed similar results at room temperature, but improved number of cycles to failure at high temperatures. The number of cycles at a given total strain range showed no large differences between the core and rim positions. By comparing with two other types of low $\gamma^{\prime}$ volume fraction nickel-based superalloys, Haynes 282 gave the best LCF properties at high temperatures. The reason may be due to the dominating transgranular fracture in the current work. A mixture of intergranular and transgranular fractures had been observed in the other alloys. The results demonstrate that heavy components of Haynes 282 can be produced with good LCF properties.
\end{abstract}

Keywords fracture surface, Haynes 282, low-cycle fatigue, nickel-based superalloy

\section{Introduction}

According to the concept of advanced ultra-supercritical (AUSC) power plants, the steam temperature should be increased to $700-750{ }^{\circ} \mathrm{C}$ (Ref 1,2$)$. The life of components at high temperature and stress conditions is limited by the properties of the materials, especially creep strength and oxidation resistance. The properties of heavy components are especially critical. For steam temperatures above $700{ }^{\circ} \mathrm{C}$, it has been found that nickel-based alloys should be applied. It has been reported that the Inconel alloy $740 \mathrm{H}$ can meet the design property requirements for boiler tubes for European and American AUSC power plants (Ref 3). On the other hand, the nickel-based superalloys are also widely used in aerospace engineering due to their high strength. The nickel-based superalloys can be classified according to their $\gamma^{\prime}$ volume fraction. The higher the $\gamma^{\prime}$ volume fraction, the more difficult it is to fabricate the materials in general.

Haynes 282 is a new wrought nickel-based superalloy designed for improved creep strength, weldability and fabricability (Ref 4). Haynes 282 is designed for applications in engines for aircraft and land-based gas turbines. This alloy has excellent creep strength, fabricability and high temperature strength. The creep strength of this alloy has surpassed that of Waspaloy $(\operatorname{Ref} 4,5)$ at the same time as the fabricability has been improved. Besides creep properties, the materials also need to have a high resistance to thermal fatigue when used in engine components subjected to cycling. The components

Junjing He and Rolf Sandström, Materials Science and Engineering, KTH Royal Institute of Technology, 10044 Stockholm, Sweden; and Sandro Notargiacomo, Centro Sviluppo Materiali S.p.A., Via di Castel Romano 100, 00128 Rome, Italy. Contact e-mails: junjing@kth.se, rsand@kth.se, and s.notargiacomo@c-s-m.it. generally undergo a certain degree of structural constraint and localized plastic flow at high temperatures. Low-cycle fatigue (LCF) is an important way to characterize the thermal fatigue properties of materials used in such conditions. Thus, it is necessary to study the LCF behavior of Haynes 282. Traditional experimental tests are conducted on small material samples designed for laboratory tests. However, for engineering use, it is necessary to test the properties of forged large ingot. It is also essential to demonstrate that the properties are satisfactory at different positions in large size components.

In this work, LCF tests of a nickel-based superalloy Haynes 282 were conducted at room temperature and high temperature with different strain amplitudes. Specimens were extracted from a large ingot at different positions. A metallographic study was conducted to reveal the fracture modes. A comparison was also made with the LCF results of other published data for this alloy, as well as with other low $\gamma^{\prime}$ volume fraction nickel-based superalloys.

\section{Experiments}

\subsection{Materials}

The material used for LCF tests was extracted from a large forged ingot with a length of $1450 \mathrm{~mm}$ and diameter of $340 \mathrm{~mm}$. The cross section of the large forged ingot was hexagonal. The ingot was forged in the work carried out within the MACPLUS project (ENER/FP7EN/249809/MACPLUS). One blank was extracted from the middle part of the ingot. For LCF tests, the specimens were taken from the rim and core of the blanks. The properties at the core and rim position were tested and compared.

The material was solution heat treated and then aged. The chemical composition of the alloy in weight percentage is as follows: Cr 20, Co 10, Mo 8.5, Ti 2.1, Al 1.5, Fe 1.5, Mn 0.3, Si $0.15, \mathrm{C} 0.06, \mathrm{~B} 0.005$ and $\mathrm{Ni}$ as balance.

\subsection{LCF at Room Temperature}

The LCF test at room temperature was conducted at CSM (Centro Sviluppo Materiali), Italy. Specimens were taken at the 
rim and core positions of the Haynes 282 forged mock-up. Four specimens at rim (S2R5, S2R6, S2R7 and S2R8) and four specimens at core ( $\mathrm{S} 2 \mathrm{C} 2, \mathrm{~S} 2 \mathrm{C} 3, \mathrm{~S} 2 \mathrm{C} 4$ and $\mathrm{S} 2 \mathrm{C} 5)$ are tested as shown in Fig. 1.

LCF tests were carried out in air in an MTS servo-hydraulic testing machine with a load cell with maximum load $\pm 100 \mathrm{kN}$. The extensometer gauge length was $10 \mathrm{~mm}$. The LCF tests were carried out according to the ASTM E606 and ISO 12106 standards. All tests were performed at room temperature $\left(25^{\circ} \mathrm{C}\right)$ in strain control with a triangular wave shape and a strain rate of $1 \times 10^{-4} \mathrm{~s}^{-1}$. Tests were carried out in fully reversed strain ratio $R=-1$ conditions. The targeted life ranges were 1000, 3000 and 10,000 cycles. Cylinder specimens with a gauge length of $19 \mathrm{~mm}$ were used for the tests.

\subsection{LCF at High Temperature}

The LCF tests at $750{ }^{\circ} \mathrm{C}$ were performed at $\mathrm{KTH}$ Royal Institute of Technology, Sweden. Again specimens were taken at the rim and core positions of the Haynes 282 forged mockup, four specimens at rim and four specimens at core.

The drawing of the specimens is shown in Fig. 2. The parallel length was $10 \mathrm{~mm}$. Tests were performed in air employing the Instron 8562 system. The extensometer measured over $25 \mathrm{~mm}$, and the strain was transferred to the parallel length $10 \mathrm{~mm}$ with the aid of FEM calculations.

Tests were performed in accordance with ASTM E606/ E606 M-12 and ISO 12106. The strain analysis was not done per ASTM/ISO because it was not possible in this case, but the FEM analysis would produce similar results. The strain ratio was -1 , which was fully reversed. The wave shape was triangular. The LCF tests were conducted with fixed strain amplitude with a strain rate of $1 \times 10^{-3} \mathrm{~s}^{-1}$. The test temperature was $750{ }^{\circ} \mathrm{C}$. The test temperature was controlled within $\pm 1{ }^{\circ} \mathrm{C}$.

Specimens for scanning electron microscopy (SEM) were prepared by mechanical grinding and polishing. Specimens

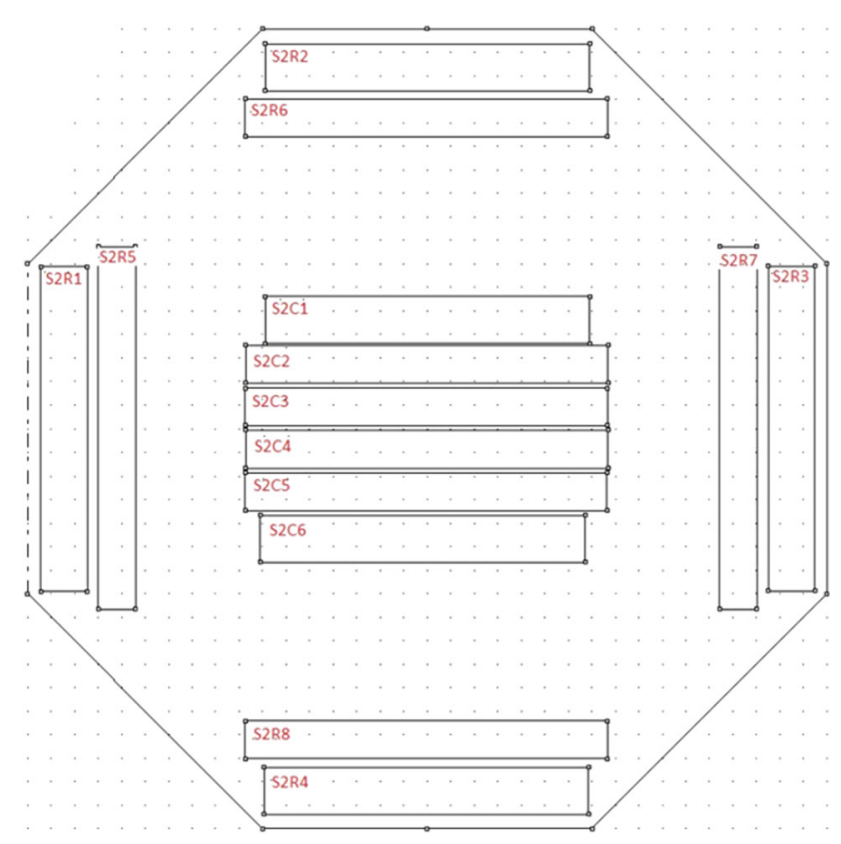

Fig. 1 Drawings for specimen positions tested by CSM, S is the abbreviation of slice, $\mathrm{R}$ for rim, $\mathrm{C}$ for core were etched with Kalling's etchant, $48 \mathrm{~g} \mathrm{CuCl}_{2}, 480 \mathrm{ml} \mathrm{HCl}$, $40 \mathrm{ml}$ distilled water, immersion for approximately $60 \mathrm{~s}$. The SEM used in this project was a Hitachi S3700 N.

\section{Results and Discussion}

\subsection{Cyclic Loading}

Figure 3 shows the stabilized hysteresis loops of LCF tests performed at room temperature for the specimens at rim and core positions. The stabilized hysteresis loops show a good consistency in terms of both load peaks and cycle area. Similar behavior is obtained at rim and core positions for the same level of strain. The stress decreases with decreasing strain amplitude.

The total strain range and plastic strain range are plotted against the number of cycles to failure for the results of the specimen at core and rim positions at temperature of 25 and $750{ }^{\circ} \mathrm{C}$ in Fig. 4 and 5. The relationship between the plastic strain range, as well as the total strain range, and the number of cycles to failure can be fitted with the Coffin-Manson equation, which is shown by the dashed lines in Fig. 4 and 5. It can be seen that the number of cycles to failure decreases with increasing total strain range and plastic strain range.

Comparing the number of cycles to failure for the tests at core and rim positions at the same temperature at a given total strain range, one can conclude that there are only modest differences. For the case at $750{ }^{\circ} \mathrm{C}$, the total strain range response for the materials at core and rim positions is almost the same. At room temperature, the specimens from the rim positions show a larger number of cycles to failure for higher total strain ranges $(>1 \%)$. From Fig. 5 it can be seen that the number of cycles to failure of the LCF test at $750{ }^{\circ} \mathrm{C}$ at the core positions is larger than that at the rim positions at a given plastic strain range.

Comparing the test results at 25 and $750{ }^{\circ} \mathrm{C}$, it is found that the total strain range response at $750{ }^{\circ} \mathrm{C}$ is close to that at $25^{\circ} \mathrm{C}$. At a given plastic strain range, the number of cycles to failure at $750{ }^{\circ} \mathrm{C}$ is $2-10$ times lower than at $25{ }^{\circ} \mathrm{C}$.

During LCF at $750{ }^{\circ} \mathrm{C}$, the test with a total strain range of $0.81 \%$ from the rim position was interrupted, so the result lies

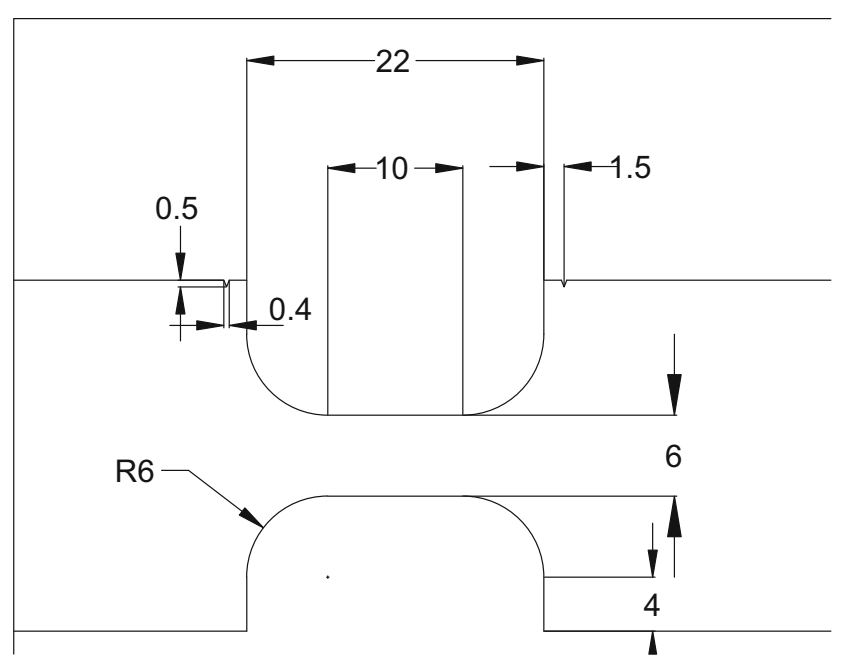

Fig. 2 Drawings of specimen design for LCF test at $750{ }^{\circ} \mathrm{C}$, with length $204 \mathrm{~mm}$ and thickness $6 \mathrm{~mm}$ 


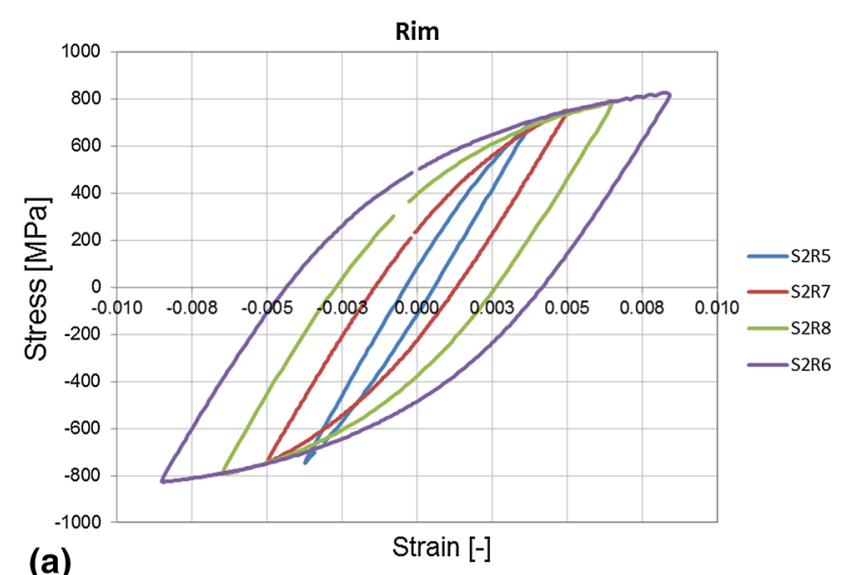

(a)

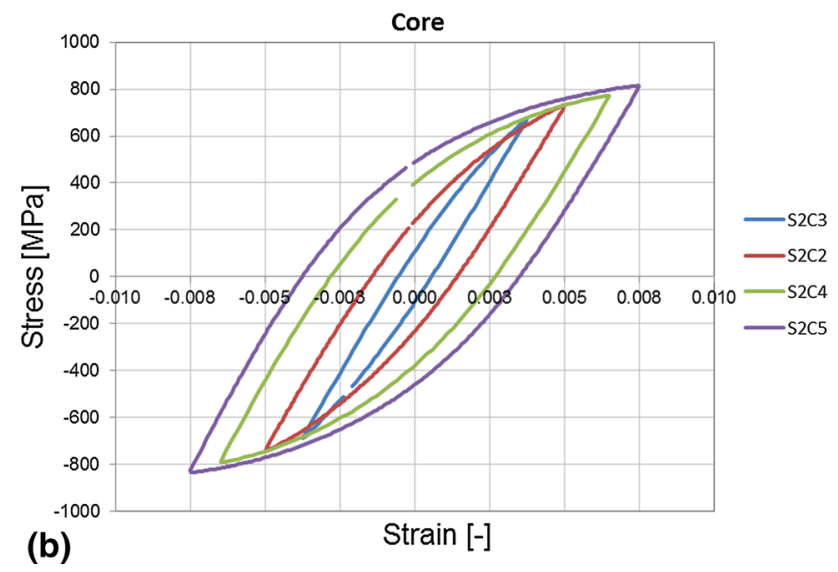

Fig. 3 Stabilized hysteresis loops of LCF at room temperature at (a) rim positions and (b) core positions

below the fitted line. In Fig. 5, there is one of the rim tests with the number of cycles to failure of 20,616 cycles, where the plastic strain range is much larger than expected. There might be something wrong with the estimation of the plastic strain from the FEM calculations. This is also reflected in Fig. 6, where there is a deviation of the stress amplitude at this point. Figure 6 shows the cyclic stress response versus the plastic strain range, where it can be readily seen that except for this deviation, both the core and rim positions can be fitted with a linear relationship. The stress amplitude is lower at high temperature. For a given plastic strain range, the rim specimens show a higher stress amplitude response than the core at both 25 and $750{ }^{\circ} \mathrm{C}$.

\subsection{Metallography Investigation}

Figure 7 shows SEM images of fatigue cracks at different positions and with different total strain ranges. It can be seen that the main failure mode is transgranular fracture. Figure 7(a) gives an overview of the fatigue cracks. Figure 7(b)-(d) shows the end of the cracks, where they are dominated by transgranular cracks. However, some parts of the cracks follow grain boundaries. From Fig. 7 (b), it can be seen that for the LCF test with a total strain range of $0.93 \%$ at rim position a crack branch appeared. Both the branches showed essentially transgranular growth. For the case of LCF test with a total strain range $0.84 \%$ at the core position, Fig. 7(c), secondary cracks were observed parallel to the main cracks. So it can be concluded that the

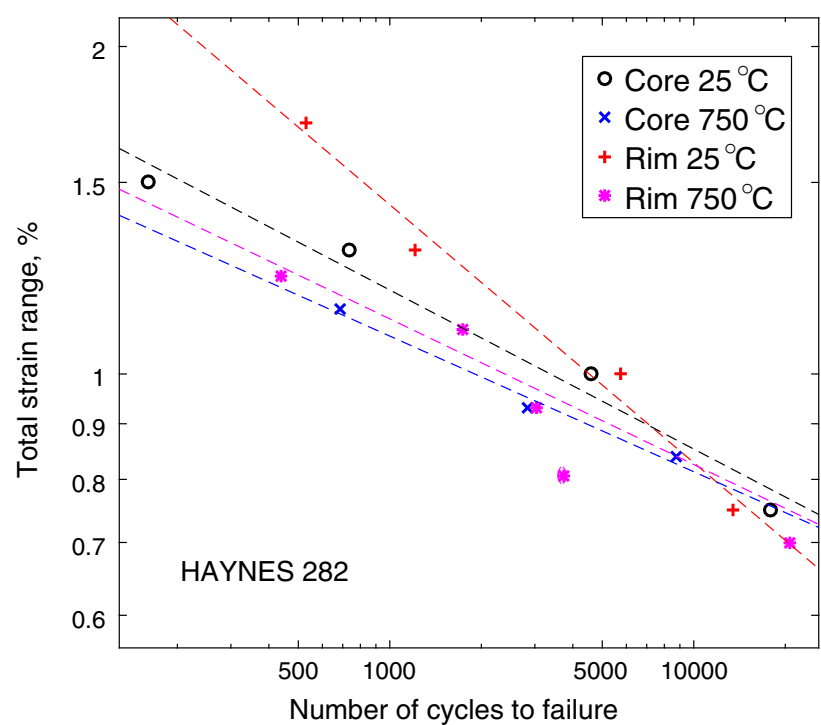

Fig. 4 Total strain range vs. number of cycles to failure at 25 and $750{ }^{\circ} \mathrm{C}$ for Haynes 282 at core and rim positions

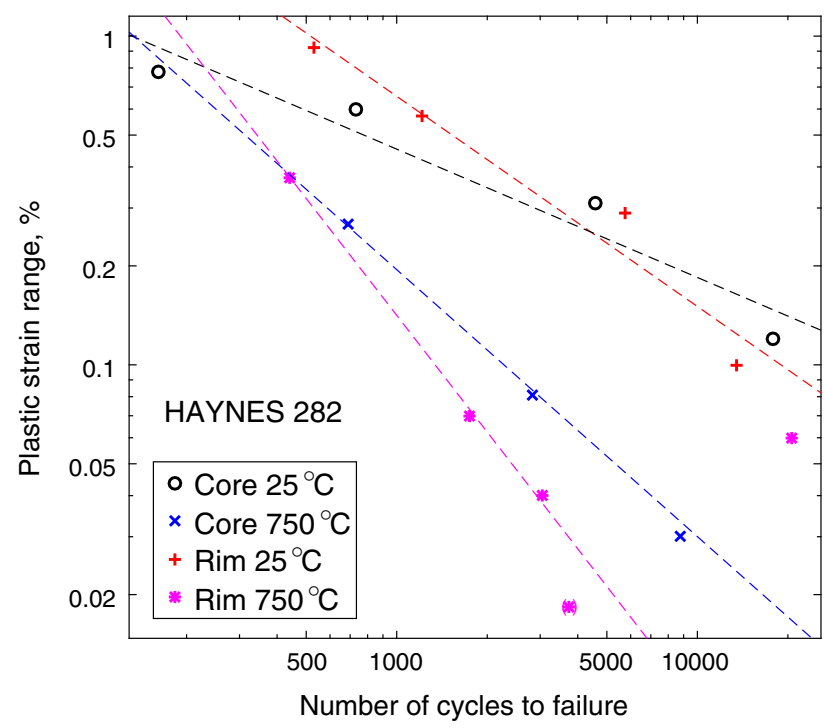

Fig. 5 Plastic strain range vs. number of cycles to failure at 25 and $750{ }^{\circ} \mathrm{C}$ for Haynes 282 at core and rim positions

failure model of the material Haynes 282 is dominated by the formation of transgranular cracks, where both the initiation and growth of the cracks occur in a transgranular way.

Figure 8 shows larger precipitates at different test conditions. The precipitates are present in both the rim and core materials. The precipitates have been identified as $(\mathrm{Ti}, \mathrm{Mo}) \mathrm{C}$ with energy-dispersive spectroscopy (EDS), as shown in Fig. 9. The (Ti,Mo)C has also been observed in (Ref 6) where only solution treatment was applied, so this kind of precipitation is not necessarily formed in the LCF tests. Moreover, precipitates were not observed around the cracks or cavities, so they are not likely to contribute to the failure of the material.

The metallography study did not demonstrate any evident difference between the core and rim material. The fatigue cracks follow the same transgranular behavior, and the precipitates also look similar. 


\subsection{Comparison with Other Tests}

There are experimental LCF data available for Haynes 282 at different temperatures (Ref 5, 7, 8). Comparison has been made between the results of the current work and the published experimental work, as shown in Fig. 10 and 11. Figure 10 shows the total strain range plotted against the number of cycles to failure at room temperature and high temperatures, $25^{\circ} \mathrm{C}$

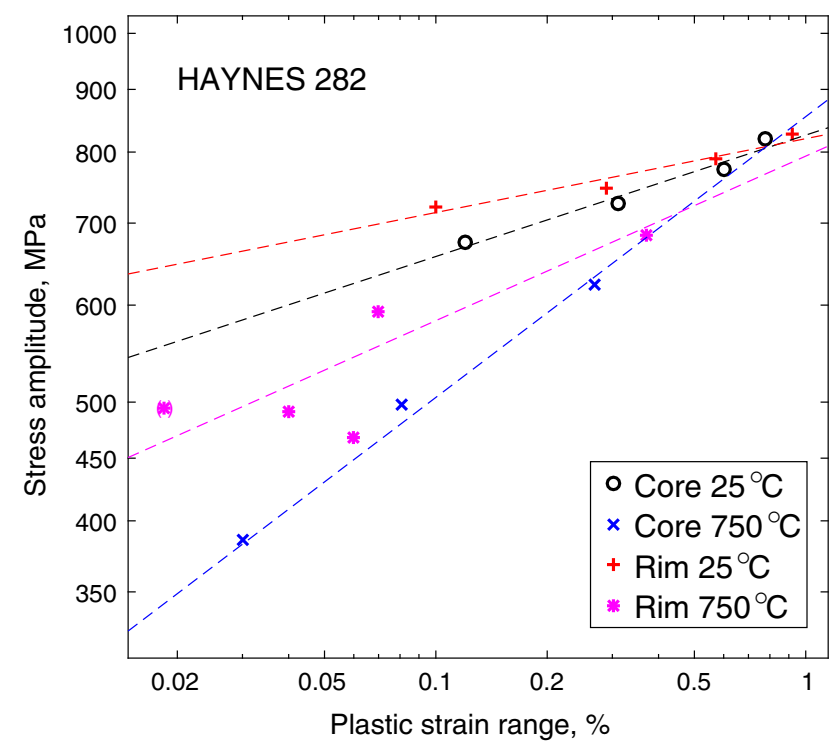

Fig. 6 Stress amplitude vs. plastic strain range at 25 and $750{ }^{\circ} \mathrm{C}$ for Haynes 282 at core and rim positions from (Ref 8) and current work, $750{ }^{\circ} \mathrm{C}$ from current work, 760 and $871{ }^{\circ} \mathrm{C}$ from Pike (Ref 5) and $730{ }^{\circ} \mathrm{C}$ from (Ref 7). At room temperature, the results from current work are similar to that of (Ref 8). However, it shows that the number of cycles to failure of the current tests at $750{ }^{\circ} \mathrm{C}$ is about a factor of 2 lower than the results obtained at room temperature and a factor of 2 higher than the results obtained at $760{ }^{\circ} \mathrm{C}$ and is in the same range as the results obtained at $730{ }^{\circ} \mathrm{C}$. The number of cycles to failure decreases in a similar way with increasing total strain range for all data. The number of cycles to failure also decreases with increasing temperature at a given total strain range.

Figure 11 shows the comparison of the cyclic stress response. The results from (Ref 8$)$ at room temperature show a very high stress amplitude, which is about 2-3 times higher than the other cases. The room temperature results are higher than those at high temperatures. The results at $730{ }^{\circ} \mathrm{C}$ and the current results at $750{ }^{\circ} \mathrm{C}$ are in the same range, whereas the ones at 760 and $871{ }^{\circ} \mathrm{C}$ show a bit lower values.

\subsection{Comparison with Other Alloys}

The results for Haynes 282 have also been compared with two other low $\gamma^{\prime}$ volume fraction nickel-based superalloys. The chemical composition of the nickel-based superalloy GH4049 (Ref 9) in weight percentage is as follows: $\mathrm{C} 0.07, \mathrm{Cr} 10.25, \mathrm{Co}$ 15, W 5.5, Mo 5, Al 4.05, Ti 1.65, V 0.35, B 0.015 and $\mathrm{Ni}$ as balance. The chemical composition of the nickel-based superalloy $75 \mathrm{Ni1} 5 \mathrm{Cr}$ (Ref 10) in weight percentage is as follows: $\mathrm{C}$ 0.042, Cr 14.5, Mo 3.18, Al 1.7, Ti 2.68, Nb 2.02, Fe $<0.1$ and $\mathrm{Ni}$ as balance.

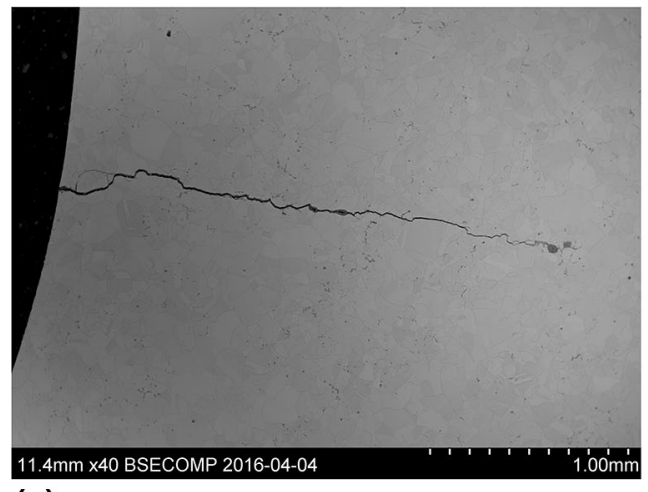

(a)

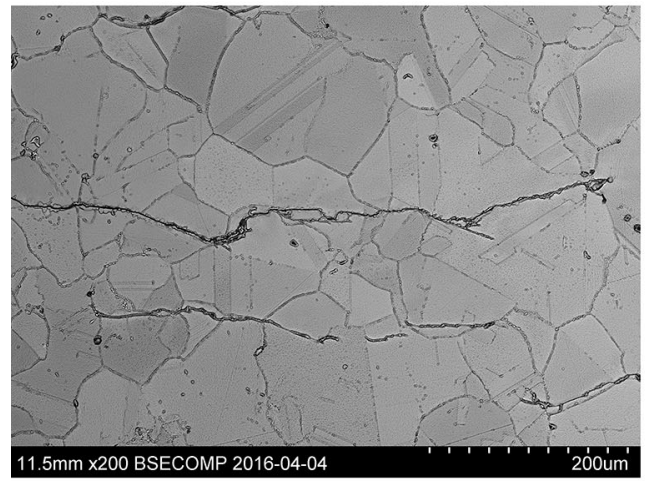

(c)

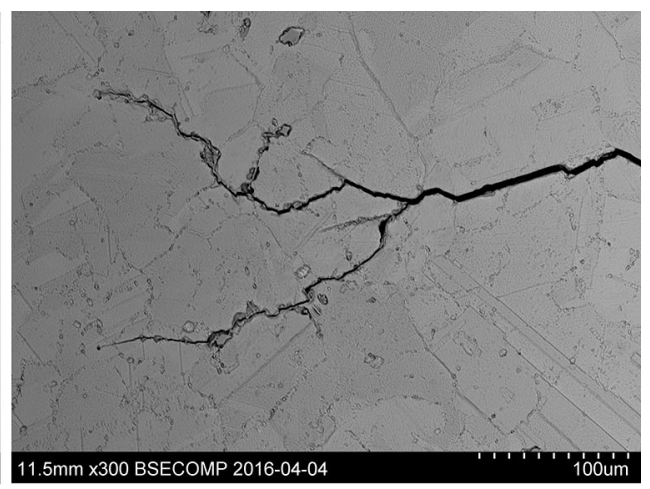

(b)

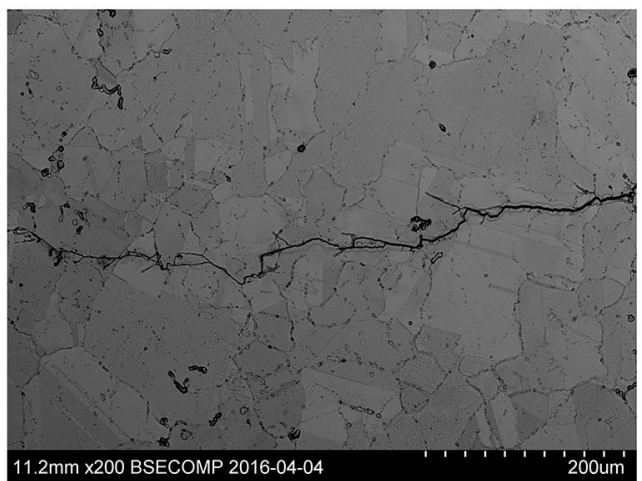

(d)

Fig. 7 SEM images of the fatigue cracks of Haynes 282 at $750{ }^{\circ} \mathrm{C}$ at different positions with different total strain ranges: (a) core, $0.93 \%$; (b) rim, $0.93 \%$; (c) core, $0.84 \%$; (d) rim, $0.7 \%$ 


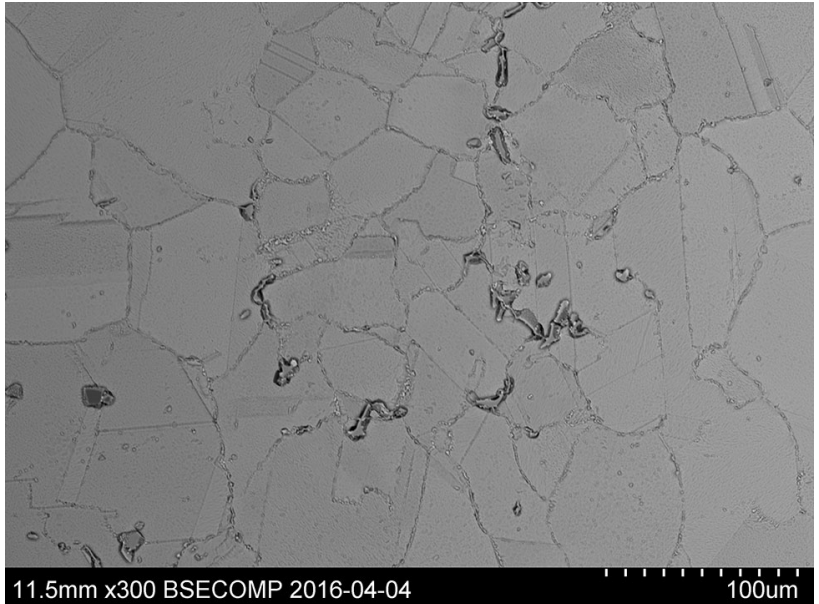

Fig. 8 SEM images of the precipitations (Ti,Mo)C in the material Haynes 282 at core positions with total strain range of $0.93 \%$

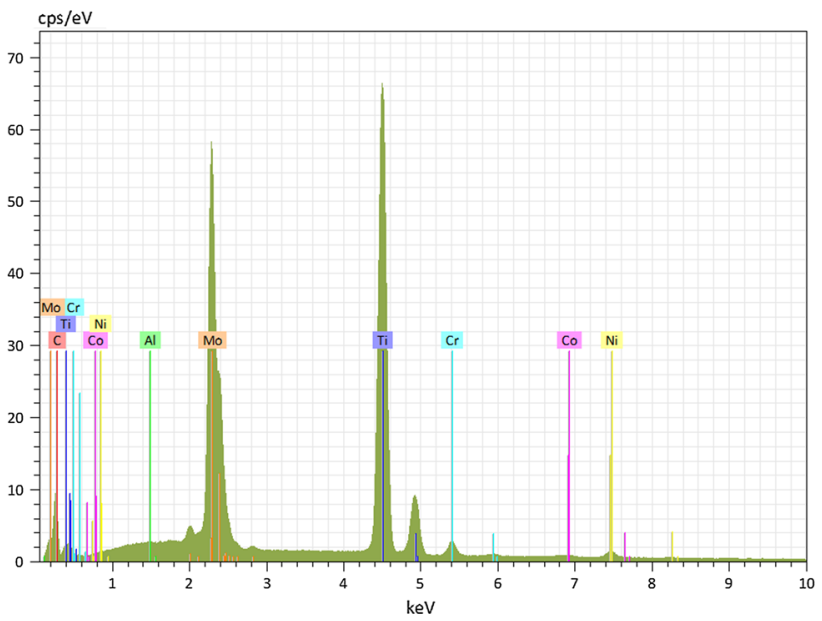

Fig. 9 EDS spectrum of a precipitate

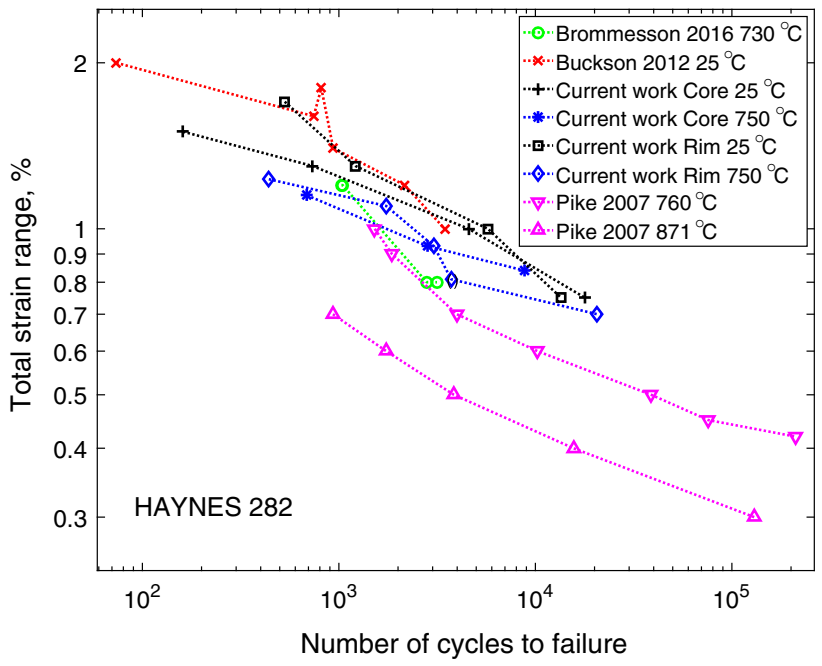

Fig. 10 Total strain range vs. number of cycles to failure for Haynes 282 at different temperatures. Experimental data from (Ref 5, 7, 8 ) are compared with current work

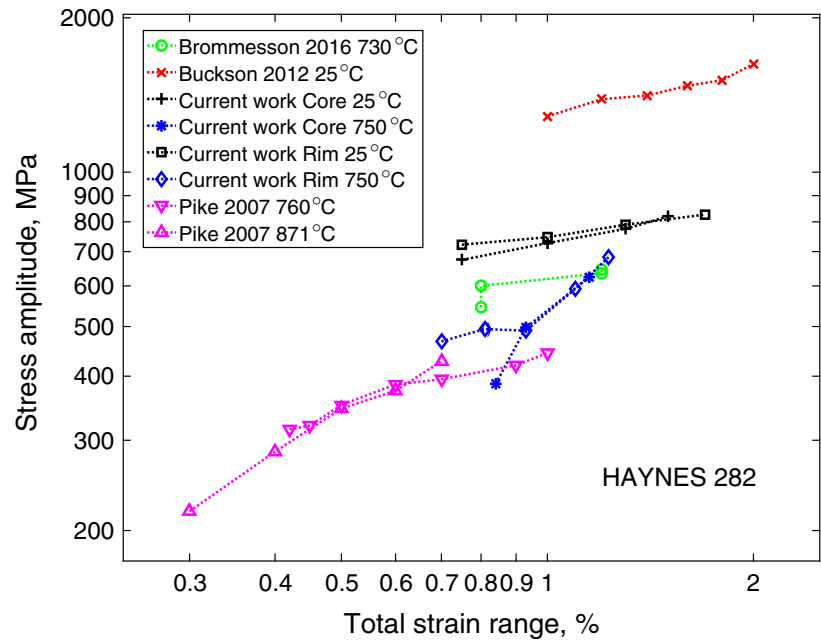

Fig. 11 Stress amplitude vs. total strain range for Haynes 282 at different temperatures. Experimental data from (Ref 5, 7, 8) are compared with current work

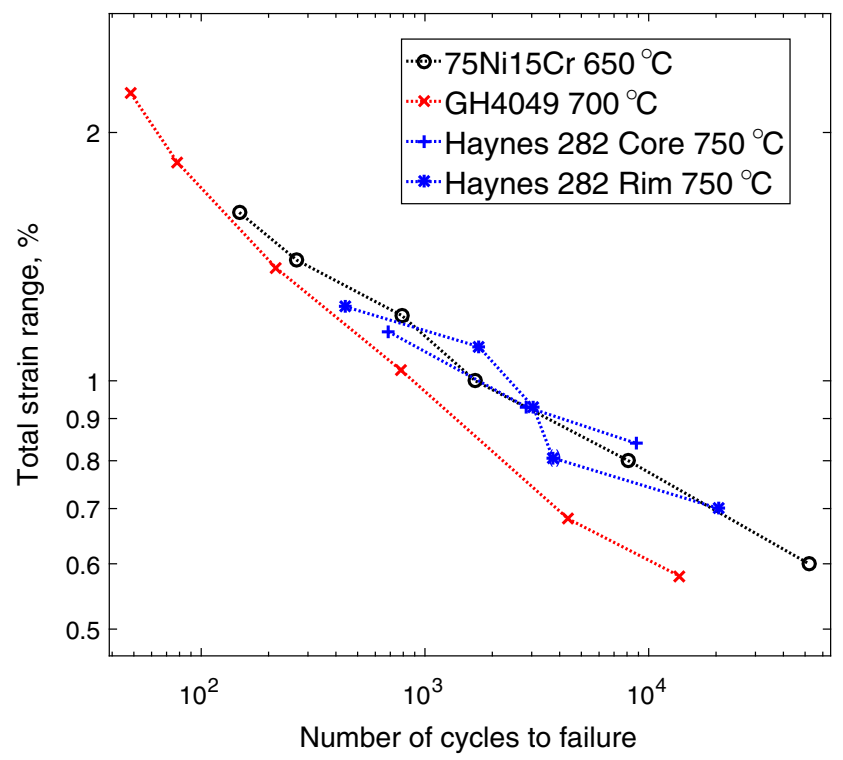

Fig. 12 Total strain range vs. number of cycles to failure for three nickel-based superalloys at $650-750{ }^{\circ} \mathrm{C}$. Experimental data from (Ref $9,10)$ are compared with current work

Figures 12 and 13 show the total and plastic strain range versus the number of cycles to failure for the three nickel-based superalloys at high temperatures ranging from 650 to $750{ }^{\circ} \mathrm{C}$ (Ref $9,10)$. Results from current work for Haynes 282 are of the same order as the others. However, it should be noted that Haynes 282 is tested at $750{ }^{\circ} \mathrm{C}$, where its number of cycles to failure is longer than that of GH4049 (Ref 9) at $700{ }^{\circ} \mathrm{C}$ at a given total strain range and plastic strain range and lies in the same range with $75 \mathrm{Ni} 15 \mathrm{Cr}$ (Ref 10 ) at $650{ }^{\circ} \mathrm{C}$. The reason might be that the fracture type observed in current work is transgranular. However, in the case of GH4049 and 75Ni15Cr (Ref 9, 10), a mixture of transgranular and intergranular rupture was found.

Figure 14 shows the cyclic stress response of the three different nickel-based superalloys, where it is seen that the 


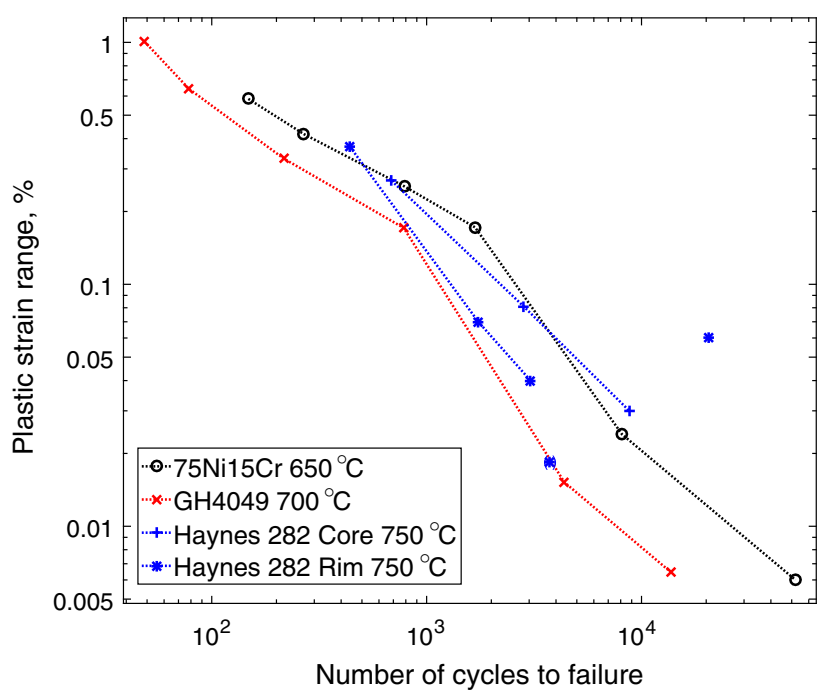

Fig. 13 Plastic strain range vs. number of cycles to failure for three nickel-based superalloys at $650-750{ }^{\circ} \mathrm{C}$. Experimental data from (Ref $9,10)$ are compared with current work

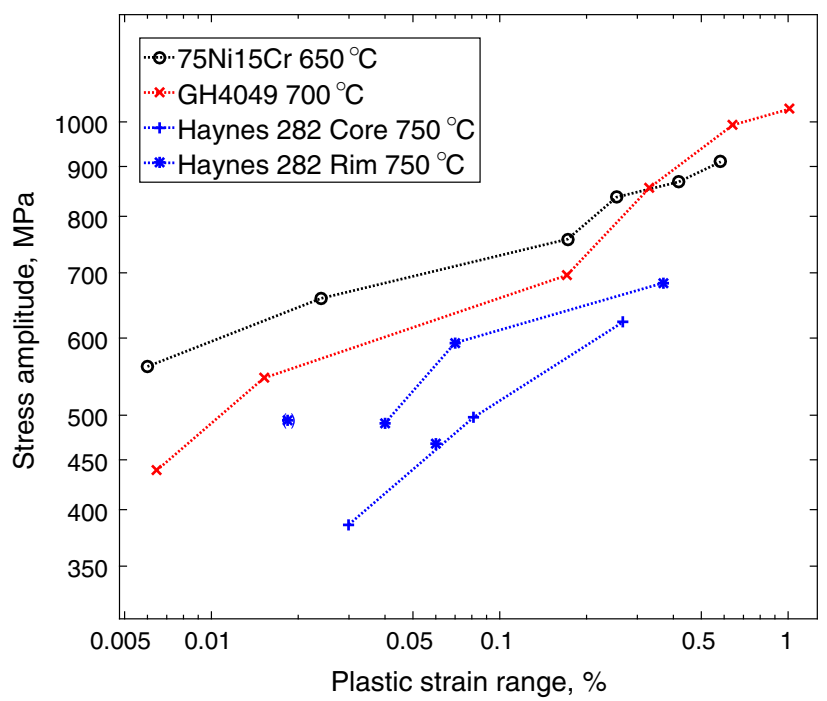

Fig. 14 Stress amplitude vs. plastic strain range for three nickelbased superalloys at $650-750{ }^{\circ} \mathrm{C}$. Experimental data from (Ref 9, 10) are compared with current work

stress amplitude of Haynes 282 is lower than that of the two other alloys at a given plastic strain range.

\section{Conclusions}

1. LCF experiments were conducted at 25 and $750{ }^{\circ} \mathrm{C}$ with a total strain range from 0.7 to $1.7 \%$ for Haynes 282 at core and rim positions from a large forged ingot. The comparison in terms of the stabilized hysteresis loops showed good consistency in terms of both load peaks and cycle area for the two positions.

2. The LCF properties of Haynes 282 from current work gave similar results to that in the literature at room tem- perature and somewhat higher number of cycles to failure at $750{ }^{\circ} \mathrm{C}$ at given total strain ranges. The cyclic stress response was consistent with results seen in the literature for Haynes 282.

3. As a function of the total strain range, the number of cycles to failure was about the same for core and rim positions. As a function of plastic strain range the rim and core curves crossed each other at both 25 and $750{ }^{\circ} \mathrm{C}$. At small strain ranges, core positions gave the best results but at higher strain ranges the situation was reversed. The data could be fitted with the Coffin-Manson relationship. The stress amplitudes of the test results from the rim positions were higher than those of the core positions at a given plastic strain range.

4. Metallography study results demonstrated that the failure mode of the material was dominated by transgranular fatigue cracks. Both the initiation and growth of the fatigue cracks were transgranular.

5. The LCF properties of Haynes 282 at $750{ }^{\circ} \mathrm{C}$ from the current work were compared with two other low $\gamma^{\prime}$ volume fraction nickel-based superalloys, where Haynes 282 shows larger number of cycles to failure at a given total strain range at high temperatures. The reason could be the difference in fracture modes. The current work showed mainly transgranular fracture, whereas the published tests had a mixture of transgranular and intergranular fracture.

\section{Acknowledgments}

This work was supported by the European Union (directorate general for energy), within the project MACPLUS [ENER/FP7EN/ 249809/MACPLUS], and the China Scholarship Council (CSC) [No. 201207090009].

\section{Open Access}

This article is distributed under the terms of the Creative Commons Attribution 4.0 International License (http://creativecommons. org/licenses/by/4.0/), which permits unrestricted use, distribution, and reproduction in any medium, provided you give appropriate credit to the original author(s) and the source, provide a link to the Creative Commons license, and indicate if changes were made.

\section{References}

1. A. Shibli, Coal Power Plant Materials and Life Assessment: Developments and Applications, Elsevier, Amsterdam, 2014

2. K. Nicol, Status of Advanced Ultra-Supercritical Pulverised Coal Technology, IEA Clean Coal Center, London, 2013

3. S.J. Patel, J.J. deBarbadillo, B.A. Baker, and R.D. Gollihue, Nickel Base Superalloys for Next Generation Coal Fired AUSC Power Plants, Proced. Eng., 2013, 55, p 246-252

4. Haynes. HAYNES ${ }^{\circledR} 282^{\circledR}$ Alloy Product Brochure. Haynes International, Kokomo

5. L.M. Pike, Low-Cycle Fatigue Behavior of HAYNES ${ }^{\circledR} 282^{\circledR}$ Alloy and Other Wrought Gamma-Prime Strengthened Alloys, American Society of Mechanical Engineers, 2007 
6. Y. Yang, R.C. Thomson, R.M. Leese, S. Roberts, Microstructural Evolution in Cast Haynes 282 for Applications in Advanced Power Plants. Advances in Materials Technology for Fossil Power Plants: Proceedings from the Seventh International Conference (EPRI 2013), D. Gandy, J. Shingledecker (eds) ASM International, Waikoloa, Hawaii, 2014, p. 143-54

7. R. Brommesson, M. Ekh, and C. Persson, Experimental Observations and Modelling of Cyclic and Relaxation Behaviour of the Ni-Based Superalloy Haynes 282, Int. J. Fatigue, 2016, 87, p 180-191
8. R.A. Buckson and O.A. Ojo, Cyclic Deformation Characteristics and Fatigue Crack Growth Behaviour of a Newly Developed Aerospace Superalloy Haynes 282, Mater. Sci. Eng. A, 2012, 555, p 63-70

9. L.J. Chen, Z.G. Wang, G. Yao, and J.F. Tian, The Influence of Temperature on Low Cycle Fatigue Behavior of Nickel Base Superalloy GH4049, Int. J. Fatigue, 1999, 21, p 791-797

10. P. Zhang, Q. Zhu, C. Hu, C.-J. Wang, G. Chen, and H.-Y. Qin, Cyclic Deformation Behavior of a Nickel-Base Superalloy Under Fatigue Loading, Mater. Des., 2015, 69, p 12-21 